\title{
Incidence and Prevalence of Spinal Cord Injury in Canada: A National Perspective
}

\author{
Vanessa K. Noonan ${ }^{\mathrm{a}}$ b Matthew Fingas ${ }^{\mathrm{a}}$ Angela Farry $^{\mathrm{a}}$ David Baxter $^{\mathrm{c}}$ \\ Anoushka Singh $^{d}$ Michael G. Fehlings ${ }^{a, d}$ Marcel F. Dvorak ${ }^{a, b}$ \\ ${ }^{a}$ Rick Hansen Institute, ${ }^{b}$ Department of Orthopaedics, University of British Columbia, and cUrban Futures Institute, \\ Vancouver, B.C., and d Department of Surgery and Spinal Program, University of Toronto, Toronto, Ont., Canada
}

\section{Key Words}

Incidence $\cdot$ Prevalence $\cdot$ Spinal cord injury

\begin{abstract}
Background: Despite decades of research, there are no national estimates of the incidence or prevalence of spinal cord injury ( $\mathrm{SCl}$ ) in Canada. Our objective was to utilize the best available data to estimate the incidence and prevalence of traumatic SCI (TSCl) and non-traumatic SCI (NTSCI) in Canada for 2010. Methods: Initial incidence (number of TSCls at injury scene) and discharge incidence (number discharged into the community) were calculated using published TSCI rates from Alberta and $\mathrm{NTSCl}$ rates from Australia. Prevalence was estimated by applying $\mathrm{TSCl}$ and $\mathrm{NTSCl}$ discharge incidence rates to historical Canadian population demographics using a cohort survival model and age-specific mortality rates for tetraplegia and paraplegia. Results: The estimated 2010 initial incidence of TSCI is 1,785 cases per year, and the discharge incidence is 1,389 (41 per million). The estimated discharge incidence for NTSCl is 2,286 cases (68 per million). The prevalence of $\mathrm{SCl}$ in Canada is estimated to be 85,556 persons ( $51 \%$ TSCI and $49 \%$ NTSCI). Conclusions: This study provides the first estimates of the incidence and prevalence of $\mathrm{SCl}$ in Canada. More populationbased studies are needed, particularly for NTSCl, as an increasing number of Canadians are expected to be affected by $\mathrm{SCl}$.

Copyright $\odot 2012$ S. Karger AG, Basel
\end{abstract}

\section{KARGER}

Fax +4161306 1234

E-Mail karger@karger.ch

www.karger.com
(C) 2012 S. Karger AG, Basel

$0251-5350 / 12 / 0384-0219 \$ 38.00 / 0$

Accessible online at:

www.karger.com/ned

\section{Introduction}

Spinal cord injury (SCI) is a devastating event causing significant burden to the individuals, their family and society. Damage to the spinal cord results in neurological impairment affecting motor, sensory and autonomic function [1]. Persons with paraplegia have damage to their thoracic, lumbar or sacral spinal cord and tetraplegia occurs with damage to the cervical cord.

Despite these immense health care and personal costs associated with SCI, there is a surprising paucity of data regarding the incidence (number of new cases of SCI that occur over a period of time) and prevalence (number of people living with SCI at a point in time) globally and in Canada particularly. Traumatic spinal cord injury (TSCI) is due to external impacts, such as a motor vehicle accident, fall or violence. Worldwide, TSCI incidence is reported to range from 10 to 83 people per million based on a literature review [2-4]. There are few studies that have examined the prevalence of TSCI, and these studies estimate it to range between 223 and 755 per million worldwide [2]. There are no current national Canadian estimates of incidence and prevalence but there have been estimates of provincial TSCI rates, which range from 24 to 53 per million [5-7].

Even less is known about the epidemiology of SCI due to non-traumatic causes (NTSCI) including spondylosis, infections or tumours. New and Sundararajan [8] recent- 
ly reported the incidence of NTSCI to be 26 cases per million people in Australia and observed a higher incidence of NTSCI than TSCI. Studies comparing patients with TSCI and NTSCI report that individuals with NTSCI are older, more likely to be female, have more comorbidities, and more frequently present with paraplegia compared to tetraplegia [9-11].

Information on the incidence and prevalence of SCI is critical for developing prevention-based strategies, health care planning, and directing future research. With an ageing population, this information is needed for both TSCI and NTSCI due to marked differences in the epidemiology. The objective of this study is to estimate the incidence and prevalence of TSCI and NTSCI in Canada using the best available evidence.

\section{Methods}

This study is the first phase of a long-term project to measure the incidence and prevalence of SCI in Canada. In the first phase described here, data from the literature were used to model estimates of the incidence and prevalence of SCI in Canada. The second phase will further refine these estimates using data from the Canadian Institute for Health Information (CIHI) which contain administrative codes for TSCI and NTSCI and data from prospective SCI databases; both sources are required due to the possibility of overestimating SCI using administrative databases [12].

\section{Identification of Studies from the Literature}

A literature search was conducted to identify original studies and review articles published between 2000 and 2010 which reported the incidence and prevalence of TSCI and NTSCI. Articles were included if the authors used a defined population to estimate the incidence rates for TSCI or NTSCI and reported the rates by age and sex.

Three studies with information on the incidence of TSCI in Canada were identified $[5,6,13]$. A study by Dryden et al. [6] which reported the incidence of TSCI in Alberta was selected to estimate the incidence and prevalence of TSCI in Canada. This study was selected because of its comprehensive research methodology: (1) three data sources (Alberta Trauma Registry, Alberta Ministry of Health and Wellness database, and death certificates from the Office of the Chief Medical Examiner) were surveyed and discrepancies among them were reconciled; (2) incidence data from April 1, 1997, to March 31, 2000, was reported; and (3) age- and sex-specific incidence of TSCI was published.

The paucity of Canadian NTSCI data necessitated that we use data from another country. In this context, Australian data are appropriate because of similarities in the socio-economic status of the population and the health care system. A study by New and Sundararajan [8] was selected to estimate NTSCI incidence because it presented incidence data from July 1, 2000 to June 30, 2006 , and reported age- and sex-specific incidence rates. A second source considered was a study by Guilcher et al. [9] that compared TSCI and NTSCI in an in-patient rehabilitation population in Canada. The selected studies are summarized in table 1 .

\section{Procedure for Estimating TSCI Incidence in Canada}

Our methodology for estimating the incidence of TSCI is illustrated in figure la. National estimates of TSCI incidence at the injury scene (the initial incidence) were calculated using 10-year age groups and sex-specific initial incidence rates published in Dryden et al. [6]. These initial incidence rates were applied to Canadian population data by age and sex from a demographic database compiled from provincial and national sources maintained by Urban Futures [14]. The product of this calculation was the estimated initial incidence of TSCI in Canada. Next, we applied post-injury mortality estimates reported by Dryden et al. [6], whereby $15.8 \%$ of individuals with TSCI died at the scene of trauma, and another $7.7 \%$ died during hospitalization, to the initial incidence values. The result of this calculation was the number of individuals who are discharged from hospital with TSCI each year (discharge incidence).

\section{Procedure for Estimating NTSCI Incidence in Canada}

The ratio of NTSCI to TSCI in the discharge population was estimated at 1.65 based on the larger number of individuals with NTSCI compared to TSCI reported in Australia [10] and Canada [9]. This ratio was applied to the discharge incidence for TSCI in Canada to determine the number of cases of NTSCI at discharge. Age- and sex-specific NTSCI incidence rates reported by New and Sundararajan [8] were then used to describe the age- and sexspecific pattern of NTSCI in Canada. While we acknowledge that the initial occurrence of NTSCI in Canada is greater than the discharge incidence, the information required to calculate the initial incidence rate for NTSCI is not available.

\section{Procedure for Estimating the Prevalence of SCI in Canada}

Our methodology for estimating the prevalence of SCI in Canada is illustrated in figure $1 \mathrm{~b}$. Prevalence was calculated using the annual discharge incidence for TSCI and for NTSCI. In order to consider the different life expectancies by severity of injury, these two groups were further disaggregated into those with paraplegia or tetraplegia (a $43.3 \%$ and $56.7 \%$ split for TSCI as reported by Dryden et al. [6] and a $69.2 \%$ and $30.8 \%$ split for NTSCI as reported by New et al. [10]) to form four SCI severity groups.

As there are no published historical estimates of SCI prevalence in Canada, it is necessary to estimate current prevalence from cumulative survivorship of annual incidence over previous time periods. We cumulated survivors for the four SCI groups annually starting with their 1921 discharge incidence populations. Annual incidence was calculated using current discharge incidence rates for TSCI and NTSCI, the estimated annual population of Canada each year, and the appropriate splits for paraplegia or tetraplegia.

Prevalence was estimated by adding to each year's discharge incidence the estimated cumulative survivors of previous years' incidence. Survivorship for each of the four SCI groups was calculated using group-, age- and sex-specific mortality rates derived from the relative life expectancy of each group relative to the average life expectancy of the population. Life expectancy for individuals with SCI by severity of injury, including no injury, is published for the United States population by age group [15]. From these data, life expectancies for people of each age living with paraplegia and tetraplegia were calculated as percentages of the average life expectancy for their peers without SCI, with the result smoothed to single years of age using a best-fit polynomial equation. The underly- 
Fig. 1. Procedure of estimating the incidence and prevalence of SCI in Canada. Incidence rates for TSCI [6] and NTSCI [8] are applied to Canadian population demographics to estimate the 2010 incidence of SCI in Canada (a). For TSCI, mortality rates from the scene of trauma and in-hospital are used to calculate a discharge incidence. Using these estimates of discharge incidence, the prevalence is modelled with a cumulative survivorship annual incidence (b).

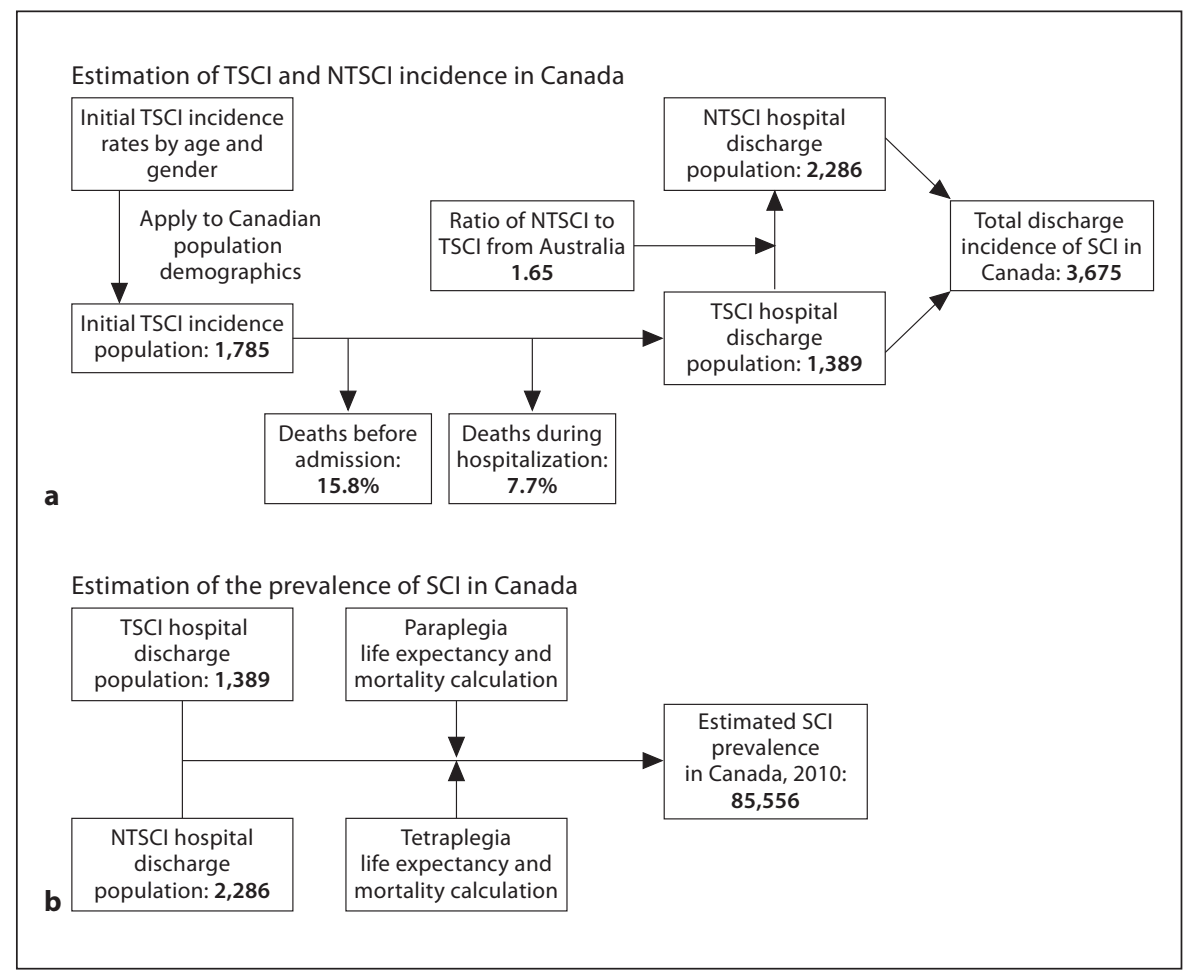

Table 1. Summary of the studies used to estimate SCI incidence and prevalence in Canada

Dryden et al. [6] New et al. [8] N N $\quad$ Guilcher et al. [9]

\section{Data source}

Type of SCI

Data time frame

Age groups included

Country

Data source

\section{TSCI}

1997-2000

all ages

Canada

Alberta Ministry of Health and Wellness;

Alberta Trauma Registry;

Office of the Medical Examiner

Method for SCI diagnosis ICD 9 CM codes

\section{Population}

Population size, $\mathrm{n}$

Age (median), years

450

35.0

Male sex, \%

$71.6(\mathrm{n}=322)$

$61.5(\mathrm{n}=277)$

Tetraplegia, \%
NTSCI

2000-2006

all ages

Australia

Victorian Admitted Episodes

Dataset for Victoria, Australia

ICD 10 AM codes
TSCI, NTSCI

2003-2005

18 years and older

Canada

National Rehabilitation

Reporting System for Ontario

Rehabilitation Client Groups
631

NR

NR

NR
NTSCI $=1002$, TSCI $=560$

$\mathrm{NTSCI}=64$

TSCI $=46$

NTSCI $=52.2(\mathrm{n}=523)$

TSCI $=75.4(\mathrm{n}=422)$

NTSCI $=18.6(\mathrm{n}=186)$

TSCI $=47.1(\mathrm{n}=264)$

$\mathrm{NR}=$ Not reported. 
Fig. 2. Age-specific incidence rates of TSCI in Canada. The incidence rates of TSCI are highest in younger population demographics (age 15-29). The age profile of the 2010 Canadian population (denoted by the line) is present for comparison.

Fig. 3. Age-specific discharge incidence rates of NTSCI in Canada. The discharge incidence rates of NTSCI are concentrated in older population demographics than TSCI (age 55-85). The age profile of the 2010 Canadian population (denoted by the line) is present for comparison.
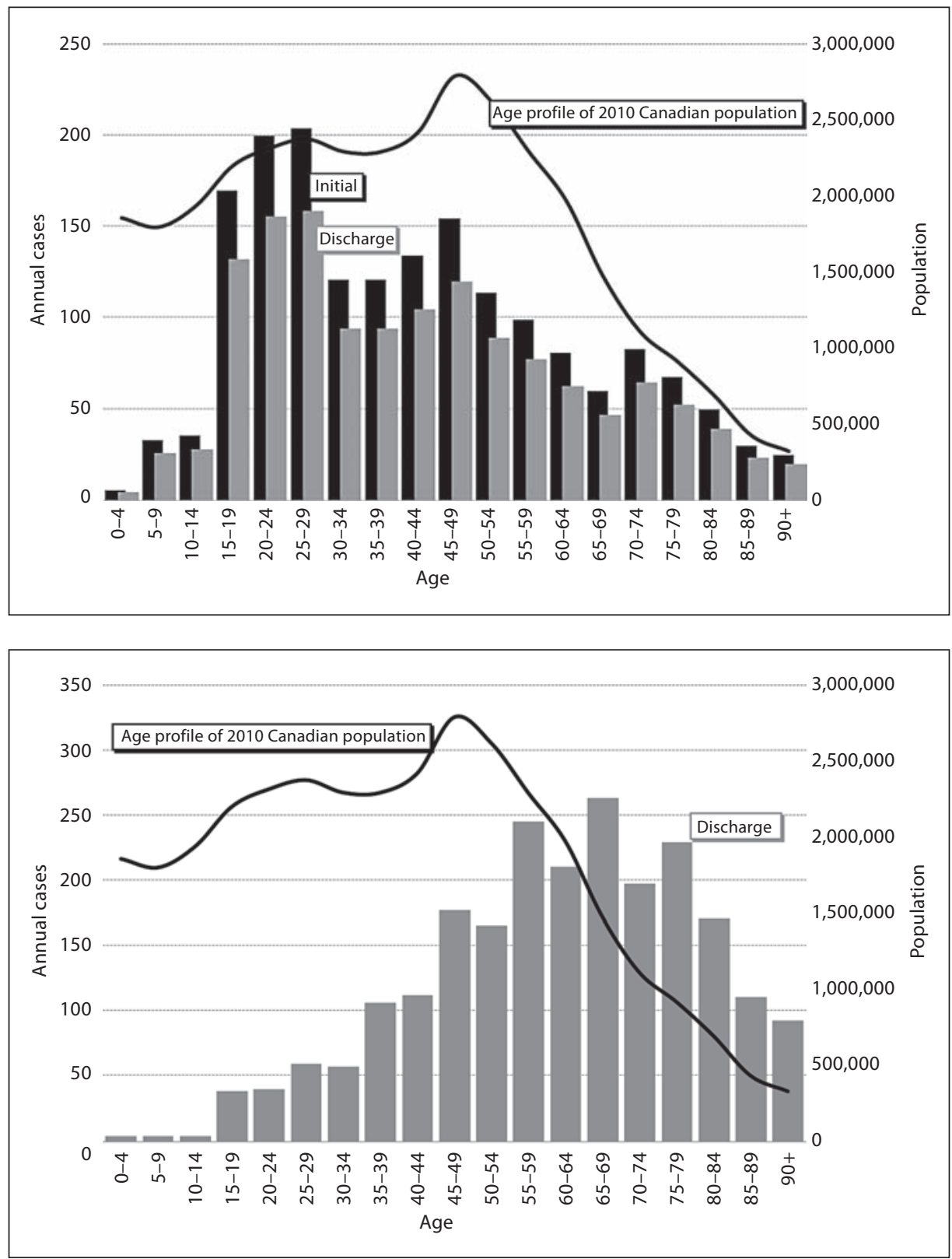

ing relative mortality rates (rates for those with SCI as a percentage of those without) were derived and applied to the average mortality rates that prevailed in each year from 1921 on.

\section{Results}

\section{Estimation of TSCI and NTSCI Incidence in Canada}

The initial incidence of TSCI in 2010 is estimated to be 1,785 injuries (53 per million) and the discharge inci- dence is 1,389 (41 per million, fig. 2). The discharge incidence for NTSCI is estimated to be 2,286 injuries in 2010 (68 per million) and the age-specific injury rates are described in figure 3. Discharge incidence was also calculated by sex (table 2) and for individuals with tetraplegia and paraplegia (data not shown).

\section{Estimation of the Prevalence of SCI in Canada}

The estimated prevalence of SCI, including both TSCI and NTSCI in Canada for 2010 is 85,556 persons, or 2,525 
Fig. 4. Age-specific prevalence estimates of SCI in Canada indicate that TSCI is concentrated in younger populations while NTSCI is concentrated in older age groups. Total prevalence of SCI in Canada, 2010, is estimated to be greater than 85,000 .

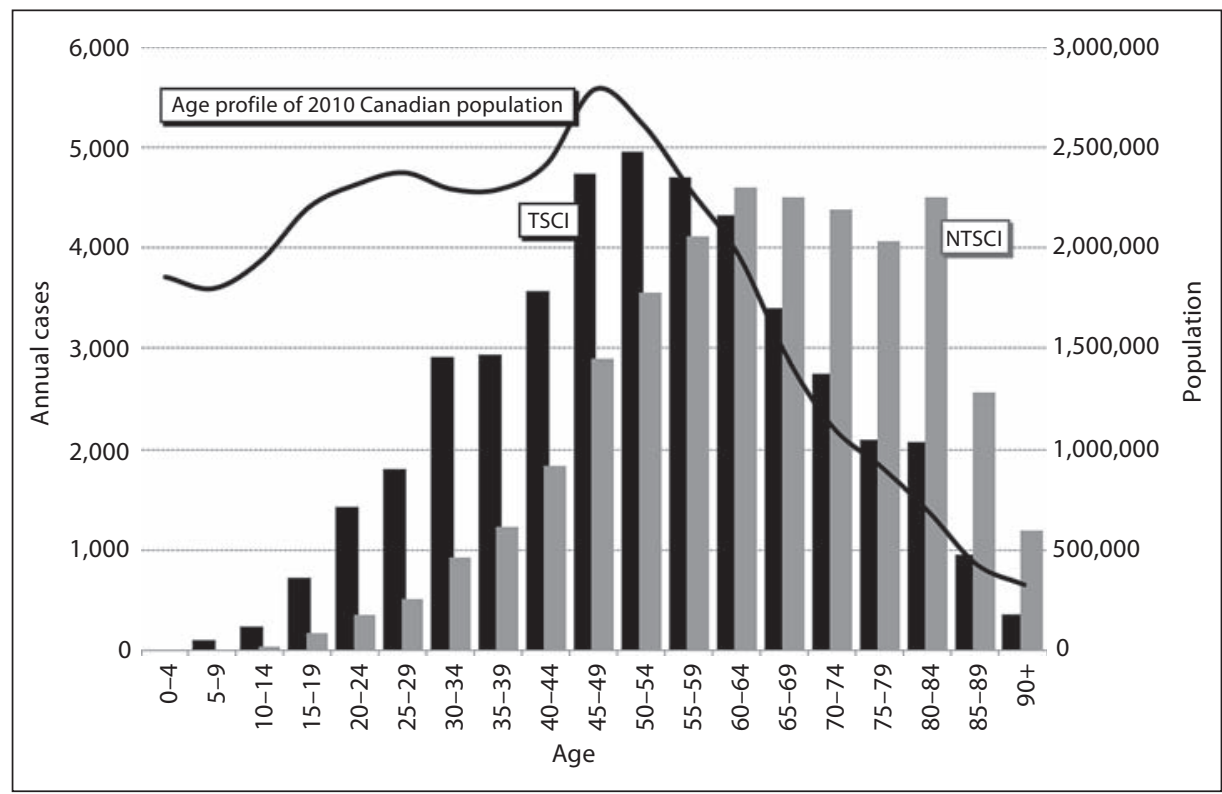

per million. Of this total, 43,974 people (51\%) would have a TSCI and 41,582 (49\%) would have an NTSCI. It is estimated that there are 37,313 people living with tetraplegia (44\%) and 48,243 people living with paraplegia (56\%) (table 3). The prevalence for TSCI and NTSCI reported by age is described in figure 4 .

\section{Discussion}

Despite many advances in SCI research over the past few decades, little is known about the incidence or prevalence of SCI. Cripps et al. [16] provided recommendations to improve the quality of these epidemiological data, including using a clear definition of the population being surveyed, differentiating TSCI and NTSCI and reporting data using international data standards. Although there have been no studies that report the incidence and prevalence of SCI in Canada, initial estimates can be obtained using studies that meet these criteria in conjunction with data on Canadian demographics. Using data from other regions to calculate the burden and even incidence and prevalence of disease has proven to be acceptable $[17,18]$. We estimate the national discharge incidence for TSCI and NTSCI to be 3,675 cases (109 per million) and the prevalence of SCI in Canada to be 85,556 in 2010.
Table 2. Age and sex discharge incidence rates of SCI in Canada for 2010

\begin{tabular}{|c|c|c|c|c|c|c|}
\hline \multirow{2}{*}{$\begin{array}{l}\text { Age } \\
\text { years }\end{array}$} & \multicolumn{2}{|c|}{ TSCI initial } & \multicolumn{2}{|c|}{ TSCI discharge } & \multicolumn{2}{|c|}{ NTSCI discharge } \\
\hline & male & female & male & female & male & female \\
\hline $0-4$ & 3.8 & 1.9 & 3.0 & 1.5 & 2.0 & 2.0 \\
\hline $5-9$ & 22 & 14.4 & 17.1 & 11.2 & 2.0 & 2.0 \\
\hline $10-14$ & 22 & 14.4 & 17.1 & 11.2 & 2.0 & 2.0 \\
\hline $15-19$ & 91 & 62.5 & 70.8 & 48.6 & 23.1 & 11.3 \\
\hline $20-24$ & 132.1 & 38.3 & 102.8 & 29.8 & 23.1 & 11.3 \\
\hline $25-29$ & 132.1 & 38.3 & 102.8 & 29.8 & 27.3 & 22.8 \\
\hline $30-34$ & 71.8 & 33.5 & 55.9 & 26.1 & 27.3 & 22.8 \\
\hline $35-39$ & 71.8 & 33.5 & 55.9 & 26.1 & 54.9 & 37.4 \\
\hline $40-44$ & 91 & 19.2 & 70.8 & 14.9 & 54.9 & 37.4 \\
\hline $45-49$ & 91 & 19.2 & 70.8 & 14.9 & 80.5 & 46.2 \\
\hline $50-54$ & 71.8 & 15.3 & 55.9 & 11.9 & 80.5 & 46.2 \\
\hline $55-59$ & 71.8 & 15.3 & 55.9 & 11.9 & 125.3 & 89.2 \\
\hline $60-64$ & 57.4 & 24.9 & 44.7 & 19.4 & 125.3 & 89.2 \\
\hline $65-69$ & 57.4 & 24.9 & 44.7 & 19.4 & 208.6 & 150.3 \\
\hline $70-74$ & 94.7 & 56.2 & 73.7 & 43.7 & 208.6 & 150.3 \\
\hline $75-79$ & 94.7 & 56.2 & 73.7 & 43.7 & 286.9 & 219.3 \\
\hline $80-84$ & 94.7 & 56.2 & 73.7 & 43.7 & 286.9 & 219.3 \\
\hline $85-89$ & 94.7 & 56.2 & 73.7 & 43.7 & 358.6 & 201.3 \\
\hline $90+$ & 94.7 & 56.2 & 73.7 & 43.7 & 358.6 & 201.3 \\
\hline
\end{tabular}


Table 3. Estimated age- and severity-specific prevalence of SCI in Canada 2010

\begin{tabular}{|c|c|c|c|c|c|c|c|c|c|}
\hline \multirow[t]{2}{*}{ Age, years } & \multicolumn{3}{|l|}{ TSCI } & \multicolumn{3}{|l|}{ NTSCI } & \multicolumn{3}{|l|}{ Total } \\
\hline & para & tetra & total & para & tetra & total & para & tetra & total \\
\hline $0-4$ & 5 & 7 & 12 & 8 & 3 & 11 & 13 & 10 & 23 \\
\hline $5-9$ & 41 & 54 & 95 & 19 & 8 & 27 & 61 & 62 & 123 \\
\hline $10-14$ & 102 & 134 & 236 & 33 & 15 & 48 & 135 & 149 & 284 \\
\hline $15-19$ & 310 & 406 & 716 & 121 & 54 & 175 & 431 & 460 & 891 \\
\hline $20-24$ & 616 & 806 & 1,422 & 253 & 113 & 366 & 869 & 919 & 1,788 \\
\hline $25-29$ & 778 & 1,019 & 1,797 & 359 & 160 & 519 & 1,138 & 1,179 & 2,317 \\
\hline $30-34$ & 1,257 & 1,646 & 2,903 & 643 & 286 & 929 & 1,900 & 1,932 & 3,832 \\
\hline 35-39 & 1,271 & 1,663 & 2,934 & 858 & 382 & 1,240 & 2,130 & 2,045 & 4,175 \\
\hline $40-44$ & 1,542 & 2,016 & 3,558 & 1,273 & 566 & 1,839 & 2,815 & 2,583 & 5,398 \\
\hline $45-49$ & 2,051 & 2,679 & 4,730 & 2,011 & 894 & 2,905 & 4,062 & 3,573 & 7,635 \\
\hline $50-54$ & 2,148 & 2,802 & 4,950 & 2,463 & 1,094 & 3,557 & 4,611 & 3,896 & 8,507 \\
\hline 55-59 & 2,040 & 2,656 & 4,696 & 2,851 & 1,265 & 4,116 & 4,891 & 3,921 & 8,812 \\
\hline $60-64$ & 1,879 & 2,437 & 4,316 & 3,191 & 1,412 & 4,603 & 5,070 & 3,849 & 8,919 \\
\hline $65-69$ & 1,482 & 1,909 & 3,391 & 3,128 & 1,379 & 4,507 & 4,610 & 3,287 & 7,897 \\
\hline $70-74$ & 1,208 & 1,537 & 2,745 & 3,053 & 1,335 & 4,388 & 4,261 & 2,873 & 7,134 \\
\hline 75-79 & 933 & 1,165 & 2,098 & 2,842 & 1,227 & 4,069 & 3,775 & 2,392 & 6,167 \\
\hline $80-84$ & 941 & 1,127 & 2,068 & 3,175 & 1,329 & 4,504 & 4,116 & 2,456 & 6,572 \\
\hline $85-89$ & 447 & 500 & 947 & 1,842 & 730 & 2,572 & 2,289 & 1,230 & 3,519 \\
\hline $90+$ & 179 & 178 & 357 & 887 & 318 & 1,205 & 1,066 & 497 & 1,563 \\
\hline Total & 19,232 & 24,742 & 43,974 & 29,011 & 12,571 & 41,582 & 48,243 & 37,313 & 85,556 \\
\hline
\end{tabular}

Data may not sum to totals due to rounding. $\mathrm{NR}=$ Not reported.

\section{Estimation of TSCI and NTSCI Incidence in Canada}

Our initial incidence rate (53 per million per year) and discharge incidence rate (41 per million per year) for TSCI are generally similar to other studies. It is difficult to make direct comparisons since other studies do not differentiate between initial and discharge incidence. However, some general comparisons can be made. A Canadian study by Pickett et al. [7] reported the lowest incidence of TSCI in children aged $0-14$ years, followed by adults aged 15-64 years, and the highest incidence was in individuals 65 and older. Our estimates follow a similar trend for age (fig. 2; table 2); using these rates and our methodology results in an estimate of 1,237 new cases of TSCI in Canada (37 per million). These Canadian estimates of TSCI incidence are considerably higher compared to Western Europe or Australia, who report an incidence rate ranging between 15 and 16 per million per year $[16,19]$ which highlights the need for more Canadian studies. Blumer and Quine [4] also reported a higher estimate for incidence and prevalence in the USA compared to non-US studies, so it may be a NorthAmerican trend.
When considering our results, it is important to review the assumptions. First, we assumed that TSCI incidence rates reported in Dryden et al. [6] by age and sex for Alberta are representative of those in Canada. In comparing the population demographics in Alberta to the rest of Canada, the Alberta population is younger (median age of 35.6 years compared to a national average of 39.5 years) and has a greater percentage of males $(51.1 \%$ compared to $49.6 \%$ nationally) [20]. This may result in overestimating TSCI, which primarily affects young adult males [14]. Second, we assumed that mortality estimates by Dryden et al. [6], both at the trauma scene and in-hospital, are representative of those in Canada and have not changed since the date of publication of the article. Future SCI studies on mortality prior to and in hospital will enable the initial and discharge incidence of TSCI to be refined.

Little is known about the incidence of NTSCI, either in Canada or elsewhere. To date, most research on the epidemiology of NTSCI has been conducted in Australia $[10,21,22]$. Given similarities in sociodemographics and health care in Canada and Australia, it is reasonable to 
assume the incidence of NTSCI would be similar; however, Canadian studies on NTSCI are needed to confirm this assumption. Secondly, NTSCI incidence was based on an assumption that the number of NTSCI cases is 1.65 times greater than TSCI cases based on an Australian study by New et al. [10]. This ratio is validated by Guilcher et al. [9] which reported a ratio of NTSCI to TSCI of 1.8 in Canada which was 1.58 after adjusting for individuals under the age of 18 . These results provide the first estimate of NTSCI in Canada and will be a starting point for future studies. Given the pattern of increasing incidence of NTSCI with age and Canada's ageing population, there will be increasing demands from NTSCI on the health care system in the future.

\section{Estimation of SCI Prevalence in Canada}

We estimate that there are 43,974 individuals living with TSCI (1,298 per million) and 41,582 (1,227 per million) living with NTSCI in Canada, 2010. The observation that the prevalence of SCI is higher in TSCI compared to NTSCI is similar to other studies [23]. Taghipoor et al. [23] reported that $63 \%$ of a community sample had TSCI, which is higher than an estimate of $51 \%$ observed in our study. However, persons with incomplete SCI (American Spinal Injury Association Impairment Scale $\mathrm{C}$ and $\mathrm{D}$ injuries) were excluded, which likely explains the higher percentage of TSCI.

Wyndaele and Wyndaele [2] and more recently Cripps et al. [16] reviewed the literature on the prevalence of TSCI world-wide. Countries such as Australia [24] and the United States [2] reported TSCI prevalence values ranging from 681 to 755 per million. Our TSCI prevalence rates are higher and may be due to a higher prevalence in Canada (an increase in TSCI which was forecasted by O'Connor [24] in 2005), differences in the characteristics of the country, and/or from the assumptions made in our calculations. A household phone survey conducted in the United States recently reported there were $1,275,000$ persons with paralysis due to SCI (TSCI and NTSCI) [25], which is equivalent to a prevalence of 4,153 per million. This is the highest SCI prevalence reported and differences are likely due to the study methodology (self-report versus medical diagnoses).

Differences in the prevalence estimates may be due to our assumptions, which are: (1) age-specific discharge incidence rates have not changed significantly; (2) the ratio of life expectancy of persons with SCI to the average life expectancies observed in the United States prevails in Canada; and (3) the ratio of life expectancy of persons with SCI compared to average life expectancies has re- mained constant and so life expectancy of persons with SCI has increased at the rate of the overall average. The approach used in our methodology captures the changes in demography and life expectancy that have occurred in Canada over the past decades but does not capture changes specific to SCI. While the methodology assumes constant incidence rates over the entire period (1921-2010), given the shorter life expectancy of those persons living with SCI compared to the overall average, effectively this presumed constancy will be for the past 20-30 years and hence should not dramatically impact the prevalence estimates. A similar situation will occur for the assumption of the constant ratio of life expectancies. Without any published benchmarks; however, it is not possible to evaluate how closely these estimates of prevalence correspond to the actual number of people living with SCI in Canada. It is also important to note that our study does not consider immigration of persons with SCI which has been identified as a possible limitation when estimating prevalence in other SCI studies [26].

\section{Conclusion}

This study provided estimates for the incidence and prevalence of TSCI and NTSCI in Canada. Analyses of registry data from the Rick Hansen Spinal Cord Injury Registry and hospital diagnostic data from CIHI will be used to refine our estimates in phase two of this project. This research will further our understanding of SCI in Canada and assist with health care planning and prevention of these devastating injuries.

\section{Acknowledgements}

This study was funded by Health Canada. The authors would like to acknowledge Dr. Hans Krueger for providing valuable feedback on the study methodology and Sophia S. Park for her assistance in formatting the manuscript.

V.K.N., M.F. and A.F. are employees of the Rick Hansen Institute. M.G.F. and M.F.D. consult for the Rick Hansen Institute.

\section{Disclosure Statement}

The authors have no conflicts of interest to disclose. 


\section{References}

1 American Spinal Injury Association: International Standards For Neurological Classification of Spinal Cord Injury, revised 2002. Chicago, American Spinal Injury Association; 2006.

$>2$ Wyndaele M, Wyndaele JJ: Incidence, prevalence and epidemiology of spinal cord injury: what learns a worldwide literature survey? Spinal Cord 2006;44:523-529.

3 van den Berg ME, Castellote JM, MahilloFernandez I, de Pedro-Cuesta J: Incidence of spinal cord injury worldwide: a systematic review. Neuroepidemiology 2010;34:184192; discussion 192.

$\checkmark 4$ Blumer CE, Quine S: Prevalence of spinal cord injury: an international comparison. Neuroepidemiology 1995;14:258-268.

5 Couris CM, Guilcher SJ, Munce SE, Fung K, Craven BC, Verrier M, Jaglal SB: Characteristics of adults with incident traumatic spinal cord injury in Ontario, Canada. Spinal Cord 2010;48:39-44.

-6 Dryden DM, Saunders LD, Rowe BH, May LA, Yiannakoulias N, Svenson LW, Schopflocher DP, Voaklander DC: The epidemiology of traumatic spinal cord injury in Alberta, Canada. Can J Neurol Sci 2003;30:113121.

7 Pickett W, Simpson K, Walker J, Brison RJ: Traumatic spinal cord injury in Ontario, Canada. J Trauma 2003;55:1070-1076.

$>8$ New PW, Sundararajan V: Incidence of nontraumatic spinal cord injury in Victoria, Australia: a population-based study and literature review. Spinal Cord 2008;46:406411.

>9 Guilcher SJ, Munce SE, Couris CM, Fung K, Craven BC, Verrier M, Jaglal SB: Health care utilization in non-traumatic and traumatic spinal cord injury: a population-based study. Spinal Cord 2010;48:45-50.
10 New PW, Simmonds F, Stevermuer T: A population-based study comparing traumatic spinal cord injury and non-traumatic spinal cord injury using a national rehabilitation database. Spinal Cord 2011;49:397-403.

11 Cosar SN, Yemisci OU, Oztop P, Cetin N, Sarifakioglu B, Yalbuzdag SA, Ustaomer K, Karatas M: Demographic characteristics after traumatic and non-traumatic spinal cord injury: a retrospective comparison study. Spinal Cord 2010;48:862-866.

12 Furlan JC, Fehlings MG: The National Trauma Registry as a Canadian spine trauma database: a validation study using an institutional clinical database. Neuroepidemiology 2011;37:96-101.

13 Pickett GE, Campos-Benitez M, Keller JL, Duggal N: Epidemiology of traumatic spinal cord injury in Canada. Spine 2006;31:799805.

14 Ramlo A, Berlin R, Baxter D: Canada to 2058: projections of demographic growth and change for Canada and its regions. Vancouver, Urban Futures Institute, 2009, Report No 74 .

15 National Spinal Cord Injury Statistical Center: The 2009 Annual Statistical Report for The Spinal Cord Injury Model Systems. Birmingham, National Spinal Cord Injury Statistical Center; 2009.

-16 Cripps RA, Lee BB, Wing P, Weerts E, Mackay J, Brown D: A global map for traumatic spinal cord injury epidemiology: towards a living data repository for injury prevention. Spinal Cord 2011;49:493-501.

17 Moradi-Lakeh M, Rasouli MR, Vaccaro AR, Saadat S, Zarei MR, Rahimi-Movaghar V: Burden of traumatic spine fractures in Tehran, Iran. BMC Public Health 2011;11:789.
18 Rahimi-Movaghar V, Moradi-Lakeh M, Rasouli MR, Vaccaro AR: Burden of spinal cord injury in Tehran, Iran. Spinal Cord 2010;48: 492-497.

19 van den Berg M, Castellote JM, Mahillo-Fernandez I, de Pedro-Cuesta J: Incidence of traumatic spinal cord injury in Aragon, Spain (1972-2008). J Neurotrauma 2011;28: 469-477.

20 Statistics Canada: The National Occupational Classification - Statistics (NOC-S) 2006 2006.

21 New PW, Rawicki HB, Bailey MJ: Nontraumatic spinal cord injury: demographic characteristics and complications. Arch Phys Med Rehabil 2002;83:996-1001.

22 New PW: Functional outcomes and disability after nontraumatic spinal cord injury rehabilitation: results from a retrospective study. Arch Phys Med Rehabil 2005;86:250261

23 Taghipoor KD, Arejan RH, Rasouli MR, Saadat S, Moghadam M, Vaccaro AR, RahimiMovaghar V: Factors associated with pressure ulcers in patients with complete or sensory-only preserved spinal cord injury: is there any difference between traumatic and nontraumatic causes? J Neurosurg Spine 2009; 11:438-444.

24 O'Connor PJ: Prevalence of spinal cord injury in Australia. Spinal Cord 2005;43:4246.

25 Cahill A, Fredine H, Zilberman L: Initial briefing: prevalence of paralysis including spinal cord injuries in the United States. Albuquerque, Centre for Development and Disability, 2008.

-26 Rahimi-Movaghar V, Saadat S, Rasouli MR, Ganji S, Ghahramani M, Zarei MR, Vaccaro AR: Prevalence of spinal cord injury in Tehran, Iran. J Spinal Cord Med 2009;32:428431. 